\title{
Comorbidities in obstructive lung disease in Korea: data from the fourth and fifth Korean National Health and Nutrition Examination Survey
}

This article was published in the following Dove Press journal:

International Journal of COPD

7 August 2015

Number of times this article has been viewed

\author{
Hee Jin Park \\ Ah Young Leem \\ Sang Hoon Lee \\ Ju Han Song \\ Moo Suk Park \\ Young Sam Kim \\ Se Kyu Kim \\ Joon Chang \\ Kyung Soo Chung
}

Division of Pulmonary and Critical Care Medicine, Department of Internal Medicine, Severance Hospital, Institute of Chest Disease, Yonsei University College of Medicine, Seoul, South Korea
Correspondence: Kyung Soo Chung Division of Pulmonary and Critical Care Medicine, Department of Internal Medicine, Severance Hospital, Yonsei University College of Medicine, 50 Yonsei-Ro, Seodaemun-gu, Seoul 120-752, South Korea

Tel +82 222274203

Fax +82 23936884

Email chungks@yuhs.ac
Background: Comorbidities can occur frequently in patients with chronic obstructive pulmonary disease (COPD) and can influence mortality and morbidity independently. It is increasingly recognized that many patients with COPD have comorbidities that have a major impact on their quality of life and survival. Therefore, we investigated the prevalence of comorbidities in Korean COPD populations.

Methods: We used data obtained in the 6 years of the fourth and fifth Korean National Health and Nutrition Examination Survey (KNHANES) IV and V. Among 50,405 subjects, 16,151 subjects aged $\geq 40$ years who performed spirometry adequately were included in this study. Airway obstruction was defined as forced expiratory volume in 1 second/forced vital capacity $<0.7$, and the Global Initiative For Chronic Obstructive Lung Disease stage was used to evaluate the severity of airway obstruction. Statistical analyses were performed using SAS 9.2.

Results: Among the 16,151 subjects (43.2\% male, 56.8\% female; mean age: 57.1 years for men and 57.2 years for women), 13.1\% had obstructive lung function; $11.3 \%$, restrictive lung function; and $75.6 \%$, normal lung function. Among individuals with obstructive lung function, $45.3 \%, 49.4 \%$, and $5.3 \%$ had mild, moderate, and severe and very severe airflow limitation. The prevalence of hypertension, diabetes mellitus (DM), underweight, and hypertriglyceridemia was higher in the obstructive lung function group than in the normal lung function group $(49.6 \% \mathrm{vs}$ $35.2 \% ; 16.8 \%$ vs $10.5 \% ; 3.3 \%$ vs $1.3 \% ; 19.7 \%$ vs $17.0 \%$ ). According to the severity of airway obstruction, hypertension and underweight were more common as severity increased, although the prevalence of DM and hypertriglyceridemia was lower in subjects with severe airway obstruction. The prevalence of hypercholesterolemia, overweight, and osteoarthritis was lower in the obstructive lung function group, especially in the severe airway obstruction groups.

Conclusions: Overall, our analysis is similar to research that was conducted earlier. Our study showed that hypertension and underweight are common comorbidities in COPD patients, and are higher as the severity of airflow obstruction increased in both men and women. DM, hypertriglyceridemia, and low high-density lipoprotein cholesterol are more common in subjects with airway obstruction, although their incidence is lower in the severe group.

Keywords: chronic obstructive pulmonary disease, comorbidity, hypertension, underweight

\section{Introduction}

Chronic obstructive pulmonary disease (COPD) is characterized by persistent airflow limitation that is usually progressive. ${ }^{1}$ COPD is a major cause of morbidity and mortality around the world. ${ }^{2}$ The frequencies of other causes of death are expected to decrease in the future, whereas COPD is expected to have a significant impact on morbidity, mortality, and health costs worldwide. ${ }^{3}$ Patients with COPD frequently show cardiovascular disease, skeletal muscle dysfunction, metabolic syndrome, 
osteoporosis, depression, and lung cancer. These can influence mortality and morbidity independently, so they should be actively looked for and treated appropriately if present. ${ }^{1,4}$ However, these comorbidities are reported to occur mainly in the West, and there are few studies of COPD comorbidities among Asian patient populations. Therefore, we investigated the prevalence of COPD comorbidities using the data from the fourth and the fifth Korean National Health and Nutrition Examination Survey (KNHANES).

\section{Material and methods Study design}

We retrospectively analyzed the database of the fourth and fifth (2007-2012) KNHANES, a nationally representative stratified random sample of 50,405 subjects who were selected from the Korean population. The KNHANES database included the results of various health-related questionnaires (eg, smoking history, income status, various diseases) by trained interviewers; physical examination (eg, blood pressure, body weight, height); laboratory studies (eg, complete blood cell, routine chemistry, lipid profile); image studies (eg, bone mineral density, joint X-ray); and pulmonary function test (PFT). Of these, 16,151 were aged $\geq 40$ years and underwent acceptable
PFT. Finally, these latter subjects were used to analyze the prevalence of COPD and the comorbidities (Figure 1). But we inevitably included subjects with airway obstruction caused by other diseases, such as asthma, pulmonary tuberculosis, and bronchiectasis, because it was not possible to exclude these diseases using inaccurate self-reported physician diagnosis criteria. So we just described these diseases and comorbidities according to a self-reported questionnaire through our available data on Table S1.

\section{Spirometry}

Pulmonary function testing was carried out by trained medical personnel using dry rolling seal spirometers (SensorMedics, Model 2130; Yorba Linda, CA, USA), which met the performance criteria of the American Thoracic Society/ European Respiratory Society (ATS/ERS). ${ }^{5}$ We analyzed prebronchodilator data from subjects aged $\geq 40$ years that performed spirometry adequately.

\section{Definition of COPD and the severity of airflow limitation}

Airflow limitation was defined as forced expiratory volume in 1 second/forced vital capacity $\mathrm{FEV}_{1} / \mathrm{FVC}\left(\% \mathrm{FEV}_{1}\right)<0.7$.

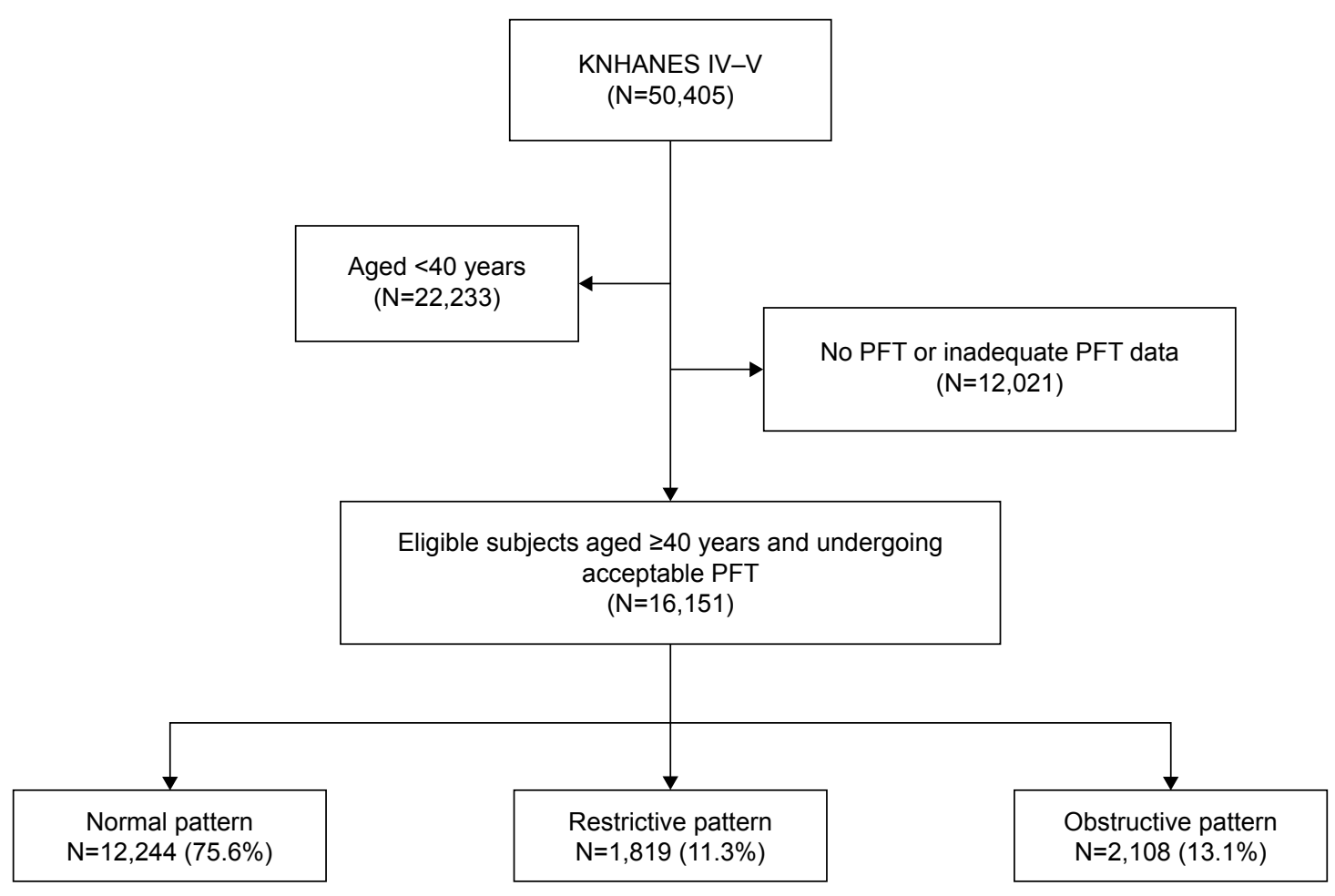

Figure I Flowchart for selection of study subjects.

Notes: Normal pattern $=\mathrm{FEV}_{1} / \mathrm{FVC} \geq 70 \%$ and $\mathrm{FEV}, \geq 80 \%$ predicted; restrictive pattern $=\mathrm{FEV}, / \mathrm{FVC} \geq 70 \%$ and $\mathrm{FEV},<80 \%$ predicted; obstructive pattern $=\mathrm{FEV} / \mathrm{FVC}<70 \%$. Abbreviations: KNHANES, Korean National Health and Nutrition Examination Survey; PFT, pulmonary function test; FEV ${ }_{1}$, forced expiratory volume in I second; FVC, forced vital capacity. 
And COPD was defined as airflow limitation in subjects aged $\geq 40$ years. The severity of airflow limitation was classified according to GOLD (Global Initiative for Chronic Obstructive Lung Disease $)^{1}$ criteria as follows:

- Mild: $\mathrm{FEV}_{1} \geq 80 \%$ predicted

- Moderate: $50 \%$ predicted $\leq \mathrm{FEV}_{1}<80 \%$ predicted

- Severe: $\mathrm{FEV}_{1}<50 \%$ predicted.

\section{Definition of comorbidities}

Hypertension, diabetes mellitus (DM), anemia, dyslipidemia, obesity, osteopenia and osteoporosis, osteoarthritis were defined as follows:

1. Hypertension: systolic blood pressure $\geq 140 \mathrm{mmHg}$ or diastolic blood pressure $\geq 90 \mathrm{mmHg}$, or on medication

2. DM: fasting blood glucose $\geq 126 \mathrm{mg} / \mathrm{dL}$ or on diabetes medication or insulin injections

3. Anemia: hemoglobin $(\mathrm{Hb})<12 \mathrm{~g} / \mathrm{L}$ in nonpregnant women aged $\geq 15$ years; $\mathrm{Hb}<11 \mathrm{~g} / \mathrm{L}$ in pregnant women and aged $\geq 15$ years; $\mathrm{Hb}<13 \mathrm{~g} / \mathrm{L}$ in men aged $\geq 15$ years

4. Dyslipidemia: defined as inclusion of one or more of the following; hypercholesterolemia, hypertriglyceridemia, low HDL (high-density lipoprotein) cholesterol, and high LDL (low-density lipoprotein) cholesterol

- Hypercholesterolemia: fasting total cholesterol $\geq 240 \mathrm{mg} / \mathrm{dL}$ or on medication

- Hypertriglyceridemia: serum triglyceride level $\geq 200 \mathrm{mg} / \mathrm{dL}$ after fasting more than 12 hours

- Low HDL cholesterol: serum HDL cholesterol level $<40 \mathrm{mg} / \mathrm{dL}$ after fasting more than 8 hours

- High LDL cholesterol: (total cholesterol - HDL cholesterol - triglyceride $\times 1 / 5) \geq 130 \mathrm{mg} / \mathrm{dL}$

5. Obesity: underweight (body mass index $<18.5 \mathrm{~kg} / \mathrm{m}^{2}$ ), normal $\left(18.5 \mathrm{~kg} / \mathrm{m}^{2} \leq\right.$ body mass index $\left.<23.0 \mathrm{~kg} / \mathrm{m}^{2}\right)$, overweight (body mass index $\geq 23.0 \mathrm{~kg} / \mathrm{m}^{2}$ ) according to the Asian body mass index cutoff by WHO expert consultation $^{6}$

6. Osteopenia $(-2.5<T$-score $<-1.0)$ and Osteoporosis ( $T$-score $\leq-2.5)$ : $T$-score was examined for the lumbar region, entire femur, and femoral neck in postmenopausal women and men aged $\geq 50$ years

7. Osteoarthritis: $\geq 50$ years old and Kellgren-Lawrence grade of knee or hip joint $\geq 2$. The Kellgren-Lawrence grade system is a method of classifying the severity of knee osteoarthritis using five grades as follows: "grade $0 "=$ no radiologic features of osteoarthritis are present; "grade 1" = doubtful joint space narrowing and possible osteophytic lipping; "grade 2 " = define osteophytes and possible joint space narrowing on anteroposterior weight-bearing radiograph; "grade 3" = multiple osteophytes, definite joint space narrowing, sclerosis, possible bony deformity; "grade 4" = large osteophytes, marked joint space narrowing, severe sclerosis, and definite bony deformity.

\section{Statistical analysis}

All values are expressed as means \pm standard deviation. The cross-sectional analysis and chi-square test were used to establish the prevalence of comorbid disease among subjects with and without COPD. A $P$-value of less than 0.05 was defined as statistically significant. Statistical analyses were carried out using SAS 9 (SAS Institute Inc. Cary, NC, USA).

\section{Ethics statement}

The Korea Center for Disease Control and Prevention (KCDC) Institutional Reviews Board approved all survey protocols (numbers 2007-02CON-04-P, 2008-04EXP-010C, 2009-01CON-03-2C, 2010-02CON-21-C, 2011-02CON06-C, 2012-01EXP-01-2C), and participants provided informed consent before partaking in the study, which was conducted in accordance with the ethical principles of the Declaration of Helsinki.

\section{Results}

\section{Characteristics of the subjects}

Among 50,405 subjects, a subgroup of 16,151 individuals aged $\geq 40$ years who performed spirometry adequately were included in this study. Among these subjects, 13.1\% had obstructive lung function, $11.3 \%$ had restrictive lung function, and $75.6 \%$ had normal lung function (Figure 1). Of the 16,151 subjects (43.2\% male, $56.8 \%$ female; mean age: 57.1 years for men and 57.2 years for women), $21.0 \%$ were current smokers, 9.6\% were ex-smokers, and $69.4 \%$ were never smokers. On average, all subjects smoked 6.6 packyears. Subjects who were male, of older age, smokers, and reported having low income were more common in the COPD group than in the normal lung function group (Table 1).

\section{Comorbidities of COPD subjects}

When compared with the normal lung function group, subjects in the obstructive lung function group had a higher prevalence of hypertension, DM, hypertriglyceridemia, low HDL cholesterol, and low body mass index (BMI <18.5). Conversely, overweight (BMI $\geq 23.0$ ), osteoarthritis, hypercholesterolemia, high LDL cholesterol, and anemia were less common in the obstructive lung function group than in the normal lung function group. In the case of osteoporosis, there was no great difference between the two groups (Table 2). 
Table I Baseline characteristics of study population

\begin{tabular}{|c|c|c|c|c|c|c|c|}
\hline \multirow[t]{3}{*}{ Characteristics } & \multirow[t]{2}{*}{ Normal } & \multirow[t]{2}{*}{ Restrictive } & \multirow[t]{2}{*}{ Obstructive } & \multicolumn{3}{|c|}{ Obstructive severity } & \multirow[t]{2}{*}{ Total } \\
\hline & & & & Mild & Moderate & Severe & \\
\hline & $12,224(75.6 \%)$ & 1,819 (1 I.3\%) & $2,108(13.1 \%)$ & 954 (45.3\%) & $\mathrm{I}, 042(49.4 \%)$ & I I 2 (5.3\%) & $16,15 \mid(100.0 \%)$ \\
\hline Age (years) & $55.8 \pm 10.7$ & $60.4 \pm 10.9$ & $64.5 \pm 10.2$ & $65.8 \pm 10.1$ & $63.2 \pm 10.3$ & $65.9 \pm 9.2$ & $57.5 \pm 11.1$ \\
\hline \multicolumn{8}{|l|}{ Age group (years) } \\
\hline $40-49(\%)$ & $4,066(33.3)$ & $350(19.3)$ & $203(9.7)$ & $72(7.5)$ & $125(12.0)$ & $6(5.3)$ & $4,619(28.6)$ \\
\hline 50-59 (\%) & $3,826(31.3)$ & $48 I(26.4)$ & $433(20.5)$ & $182(19.1)$ & $230(22.1)$ & $21(18.8)$ & $4,740(29.3)$ \\
\hline $60-69(\%)$ & $2,74 \mathrm{I}(22.4)$ & $559(30.7)$ & $730(34.6)$ & $315(33.0)$ & $378(36.3)$ & $37(33.0)$ & $4,030(25.0)$ \\
\hline$\geq 70$ (\%) & I,591 (13.0) & $429(23.6)$ & $742(35.2)$ & $385(40.4)$ & 309 (29.7) & $48(42.9)$ & $2,762(17.1)$ \\
\hline \multicolumn{8}{|l|}{ Sex } \\
\hline Male & 4,695 (38.4) & $849(46.7)$ & $\mathrm{I}, 434(68.0)$ & $664(69.6)$ & $695(66.7)$ & $75(67.0)$ & $6,978(43.2)$ \\
\hline Female & $7,529(61.6)$ & $970(53.3)$ & $674(32.0)$ & $290(30.4)$ & $347(33.3)$ & $37(33.0)$ & $9,173(56.8)$ \\
\hline \multicolumn{8}{|l|}{ Smoking status ${ }^{\mathrm{a}}$} \\
\hline Never & $7,920(73.6)$ & I,057 (7I.I) & $667(42.8)$ & $284(42.1)$ & $355(44.7)$ & $28(31.8)$ & $9,644(69.4)$ \\
\hline Former & $866(8.1)$ & $191(12.8)$ & $274(17.6)$ & $115(17.0)$ & $133(16.8)$ & $26(29.6)$ & $1,331(9.6)$ \\
\hline Current & I,973 (18.3) & $329(22.1)$ & $616(39.6)$ & $276(40.9)$ & $306(38.5)$ & $34(38.6)$ & $2,918(21.0)$ \\
\hline Pack-year & $5.3 \pm 12.9$ & $7.5 \pm 16.5$ & $15.5 \pm 20.7$ & $14.8 \pm 19.9$ & $15.8 \pm 20.9$ & $19.7 \pm 25.0$ & $6.6 \pm 14.6$ \\
\hline \multicolumn{8}{|c|}{ Household income (quartile) } \\
\hline First quartile & $2,491(20.6)$ & $505(28.2)$ & 698 (33.7) & $332(35.5)$ & $316(30.9)$ & $50(45.9)$ & $3,694(23.2)$ \\
\hline Second quartile & $3,012(25.0)$ & $423(23.6)$ & $546(26.4)$ & $223(23.8)$ & $297(29.0)$ & $26(23.9)$ & $3,981(25.0)$ \\
\hline Third quartile & $3,041(25.2)$ & $422(23.6)$ & $418(20.2)$ & $180(19.2)$ & $219(21.4)$ & $19(17.4)$ & $3,88 \mathrm{I}(24.4)$ \\
\hline Fourth quartile & $3,522(29.2)$ & $440(24.6)$ & 407 (19.7) & $20 \mathrm{I}(2 \mathrm{I} .5)$ & $192(18.8)$ & 14 (I2.8) & $4,369(27.4)$ \\
\hline
\end{tabular}

Notes: Data are presented as numbers (percentages) for categorical variables. Continuous variables are presented as means \pm standard deviations. ${ }^{2}$ The sums of some data do not equal the total due to missing data; normal $=\mathrm{FEV}, / \mathrm{FVC} \geq 70 \%$ and $\mathrm{FEV}, \geq 80 \%$ predicted; restrictive $=\mathrm{FEV}, \mathrm{FVC} \geq 70 \%$ and $\mathrm{FEV},<80 \%$ predicted; obstructive $=\mathrm{FEV}, \mathrm{F}$ $\mathrm{FVC}<70 \%$ predicted; mild $=\mathrm{FEV}_{1} \geq 80 \%$ predicted; moderate $=50 \% \leq \mathrm{FEV},<80 \%$ predicted; severe $=\mathrm{FEV}_{1}<50 \%$ predicted.

Abbreviations: $\mathrm{FEV}_{1}$, forced expiratory volume in I second; FVC, forced vital capacity.

Table 2 Comorbidities according to lung function

\begin{tabular}{|c|c|c|c|c|c|c|c|}
\hline \multirow[t]{3}{*}{ Comorbidity } & \multirow[t]{2}{*}{ Normal } & \multirow[t]{2}{*}{ Restrictive } & \multirow[t]{2}{*}{ Obstructive } & \multicolumn{3}{|c|}{ Obstructive severity } & \multirow[t]{3}{*}{$P$-value } \\
\hline & & & & Mild & Moderate & Severe & \\
\hline & I 2,224 (75.6\%) & $1,819(11.3 \%)$ & $2,108(13.1 \%)$ & $954(45.3 \%)$ & I,042 (49.4\%) & I I 2 (5.3\%) & \\
\hline Hypertension & $4,237(35.2)$ & $936(52.2)$ & $1,035(49.6)$ & $456(48.2)$ & $519(50.4)$ & $60(54.1)$ & $<0.001$ \\
\hline DM & $1,206(10.5)$ & $345(20.4)$ & $329(16.8)$ & $137(15.6)$ & I78 (|8.2) & $14(13.9)$ & $<0.001$ \\
\hline Anemia & $\mathrm{I}, 028(8.7)$ & $176(10.2)$ & $153(7.6)$ & $73(8.0)$ & $71(7.1)$ & $9(8.5)$ & 0.074 \\
\hline Dyslipidemia & $6,982(70.0)$ & $\mathrm{I}, 128(76.6)$ & I,253 (72.7) & $557(71.0)$ & $642(64.3)$ & $54(64.3)$ & $<0.001$ \\
\hline Hypercholesterolemia & I,964 (I7.I) & $354(21.0)$ & $305(15.6)$ & $122(13.9)$ & $170(17.4)$ & $13(13.0)$ & $<0.001$ \\
\hline Hypertriglyceridemia & $\mathrm{I}, 640(17.0)$ & $299(21.6)$ & $337(19.7)$ & $150(19.3)$ & I 75 (20.8) & $12(13.3)$ & $<0.001$ \\
\hline Low HDL cholesterol & $2,742(25.1)$ & $522(32.9)$ & $635(34.0)$ & $296(35.1)$ & $310(33.3)$ & $29(31.2)$ & $<0.001$ \\
\hline High LDL cholesterol & $3,846(35.8)$ & $515(33.2)$ & $554(30.6)$ & $232(28.8)$ & $294(32.1)$ & $28(31.5)$ & $<0.001$ \\
\hline \multicolumn{8}{|l|}{ Obesity } \\
\hline $18.5 \mathrm{~kg} / \mathrm{m}^{2}>\mathrm{BMI}$ & $153(1.2)$ & $31(1.7)$ & $70(3.3)$ & $18(1.9)$ & $33(3.2)$ & $19(17.4)$ & $<0.001$ \\
\hline $18.5 \mathrm{~kg} / \mathrm{m}^{2} \leq \mathrm{BMI}<23.0 \mathrm{~kg} / \mathrm{m}^{2}$ & $7,616(62.4)$ & $832(46.2)$ & $\mathrm{I}, 435(68.2)$ & $691(72.4)$ & $671(64.4)$ & $73(67.0)$ & \\
\hline $23.0 \mathrm{~kg} / \mathrm{m}^{2} \leq \mathrm{BMI}$ & $4,437(36.4)$ & $939(52.1)$ & $600(28.5)$ & $245(25.7)$ & $338(32.4)$ & $17(15.6)$ & \\
\hline \multicolumn{8}{|l|}{ Osteoporosis ${ }^{\mathrm{a}}$} \\
\hline Osteopenia & $406(5.0)$ & $63(4.3)$ & $5 \mathrm{I}(2.7)$ & $19(2.2)$ & $29(3.2)$ & $3(2.8)$ & 0.954 \\
\hline Osteoporosis & $223(2.7)$ & $36(4.3)$ & $35(2.7)$ & $12(1.4)$ & $20(2.2)$ & $3(2.8)$ & \\
\hline Osteoarthritis ${ }^{\mathrm{a}}$ & $\mathrm{I}, 040(12.7)$ & $200(13.6)$ & $226(11.9)$ & 121 (I3.7) & $98(10.7)$ & $7(6.6)$ & $<0.001$ \\
\hline
\end{tabular}

Notes: Data are presented as numbers (percentages) for categorical variables. ${ }^{\mathrm{D} D a t a}$ do not equal the total because evaluations for osteoporosis and osteoarthritis were only performed in subjects aged $\geq 50$ years (normal $=8,158$; restrictive $=1,469$; obstructive $=1,905$; mild $=882$; moderate $=917$; severe $=106$ ); normal $=\mathrm{FEV} / \mathrm{FVC} \geq 70 \%$ and $\mathrm{FEV}, \geq 80 \%$ predicted; restrictive $=\mathrm{FEV}, / \mathrm{FVC} \geq 70 \%$ and $\mathrm{FEV},<80 \%$ predicted; obstructive $=\mathrm{FEV}, / \mathrm{FVC}<70 \%$ predicted; Mild $=\mathrm{FEV}, \geq 80 \%$ predicted; moderate $=50 \% \leq$ $\mathrm{FEV},<80 \%$ predicted; severe $=\mathrm{FEV},<50 \%$ predicted.

Abbreviations: BMI, body mass index; DM, diabetes mellitus; $\mathrm{FEV}_{\mathrm{l}}$, forced expiratory volume in I second; FVC, forced vital capacity; HDL, high density lipoprotein; LDL, low density lipoprotein. 


\section{Comorbidities according to sex and lung function in subjects with obstructive airflow limitation}

We analyzed comorbidities according to sex and the severity of COPD. Among individuals with obstructive lung function, $45.3 \%$ had mild disease, $49.4 \%$ had moderate disease, and $5.3 \%$ had severe disease. Hypertension was more common as the airway limitation became more severe. Although the prevalence of DM, hypertriglyceridemia, hypercholesterolemia, and overweight were lower in subjects with severe airway obstruction, the prevalence of underweight increased, but low HDL cholesterol decreased with the severity of obstruction. On the other hand, the prevalence of osteoarthritis decreased with increasing severity of airway obstruction. Osteoporosis seemed to have a higher prevalence as the severity of obstruction increased, but the prevalence of osteopenia in the groups with more severe disease was lower than that in the normal lung function group (Table 2).

When the subjects were divided into men and women, the numbers of ever smokers ( $50.9 \%$ vs $23.7 \%)$, DM (17.3\% vs $12.0 \%)$, hypertriglyceridemia $(17.6 \%$ vs $12.6 \%)$, and low HDL cholesterol (35.0\% vs $19.7 \%$ ) were higher in men with obstructive lung function than in women with obstructive lung function. In contrast, women with obstructive lung function more frequently had hypercholesterolemia (18.0\% vs $12.8 \%$ ), high LDL cholesterol (31.9\% vs $23.6 \%$ ), osteoarthritis $(18.3 \%$ vs $8.9 \%)$, anemia ( $9.5 \%$ vs $6.2 \%)$, and osteoporosis (5.0\% vs $1.0 \%$ ) (Table 3). Hypertension, underweight, overweight, and osteoarthritis showed similar trends between men and women (Figure 2). However, there were differences in trends for dyslipidemia between men and women. In men, the prevalence of all kinds of dyslipidemia decreased in the severe obstructive lung function group; in women, the prevalence of dyslipidemia increased rather than decreased in the severe obstructive lung function group, with the exception of hypercholesterolemia (Figure 3A-D).

\section{Discussion}

Most COPD patients also show other diseases that may affect the prognosis. Compared with patients without COPD, patients with COPD had more than twice the number of comorbidities, longer hospital stays, and higher in-hospital mortality rates. Some of these diseases are independently generated, regardless of COPD, but some others share risk factors, such as smoking, or increase the risk of one another. Systemic inflammation, which is characteristic of COPD, is common in other comorbidities, and is thought to be the mechanism that connects COPD with other comorbidities. ${ }^{7}$
Because COPD often develops in long-time smokers in middle age, patients frequently have a variety of other diseases related to either smoking or aging. ${ }^{8} \mathrm{COPD}$ itself also has significant extrapulmonary effects including weight loss, nutritional abnormalities, and skeletal muscle dysfunction. It can contribute to exercise intolerance and poor health status in patients with COPD. ${ }^{9}$

In this study, as in the previous study, hypertension, DM, and dyslipidemia were more common in COPD patients. However, when we divided the subjects by severity and sex, the results of this study were rather dissimilar to those of the previous study.

In COPD subjects, the prevalence of obesity was $23 \% .{ }^{10-13}$ The mean BMI was $>25 \mathrm{~kg} / \mathrm{m}^{2}$ in Western countries, including Austria, Germany, Canada, and the United States, whereas in the People's Republic of China and the Philippines, mean BMI of COPD subjects was 23.3 and $24.9 \mathrm{~kg} / \mathrm{m}^{2}$, respectively. ${ }^{14}$ In a previous study in Korea, obesity (BMI $\geq 23 \mathrm{~kg} / \mathrm{m}^{2}$ ) was observed in $23.5 \%$ of COPD patients. ${ }^{15}$ In our study, prevalence of obesity (BMI $\geq 23 \mathrm{~kg} / \mathrm{m}^{2}$ ) was $28.5 \%$, and mean BMI was $24.2 \mathrm{~kg} / \mathrm{m}^{2}$. Prevalence of obesity and mean BMI can vary depending on country and race. However, most available data suggest that obesity is more prevalent in patients with COPD than in the general population, depending on the severity of chronic airflow limitation; an exception was the study by Steuten et a ${ }^{16}$ who had reported that the rate of obesity decreased in subjects with severe airway obstruction. As in our study, a previous study reported in Korea showed that subjects with airway obstruction had lower BMI and fat free mass index values, and the reductions were prominent in subjects with severe airway obstruction. ${ }^{17}$ These data showed the pathognomonic relationship between BMI and the degree of airway obstruction in Asians, including Koreans. Increased work of breathing, higher total daily energy expenditure, catabolic energy balances, and systemic inflammatory responses can be causes of low BMI ${ }^{18-20}$ Moreover, low BMI can also be an independent risk factor for mortality in patients with COPD. ${ }^{21,22}$ Therefore, physicians should pay more attention to the nutritional and functional status of patients with COPD.

Cardiovascular disease is the most important and the most frequent comorbidity in COPD. ${ }^{8}$ Hypertension is the most important factor in cardiovascular disease, and it has a major influence on prognosis. ${ }^{7}$ In Western countries, approximately $17 \%-55 \%$ of COPD patients had hypertension; ${ }^{12,23-28}$ a previous study in Korea reported a prevalence of $39.4 \% .{ }^{15}$ Although in COPD patients, the mechanism of cardiovascular disease - including hypertension - is not yet quite clear, 


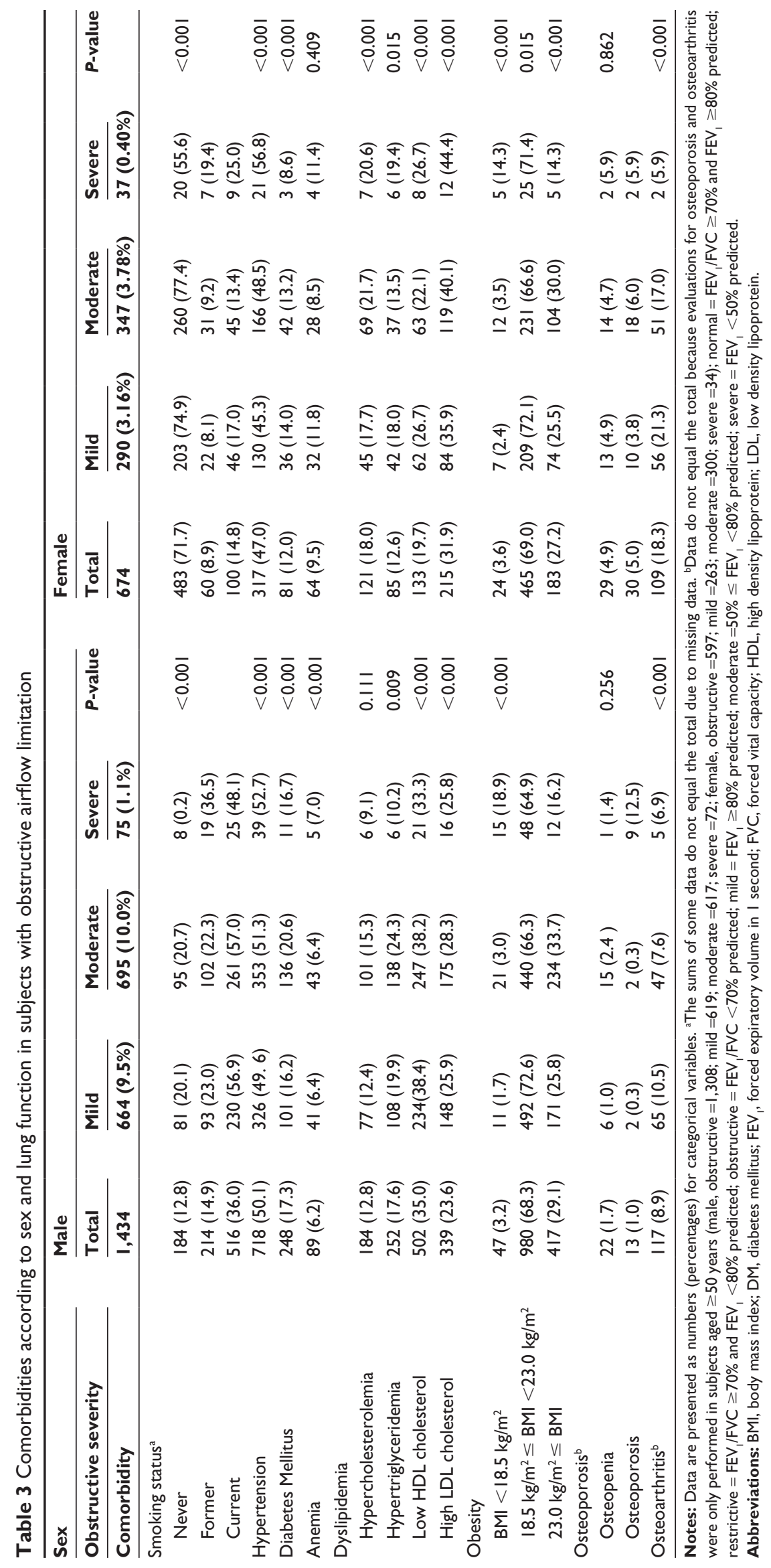


A

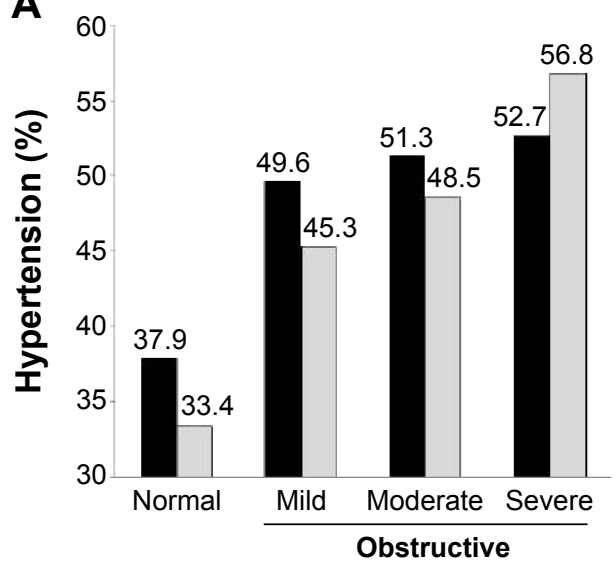

C

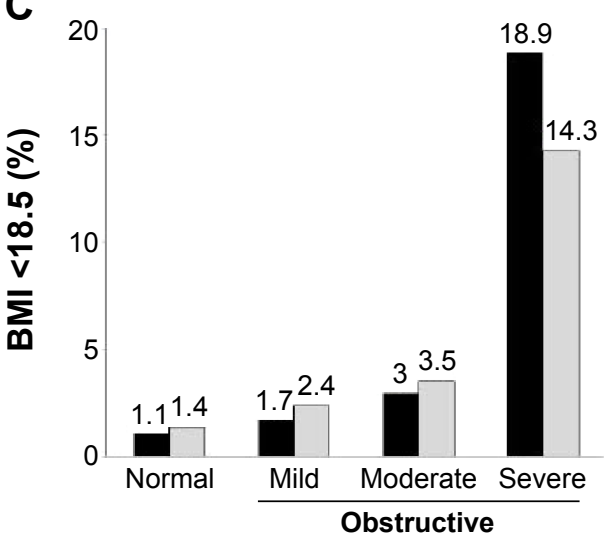

B

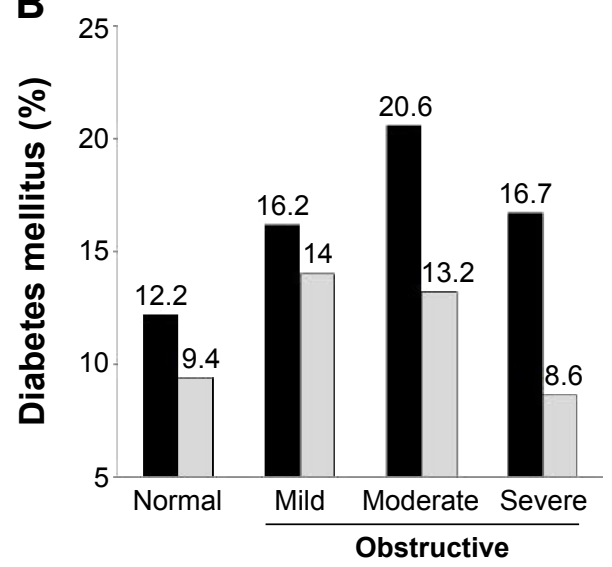

D

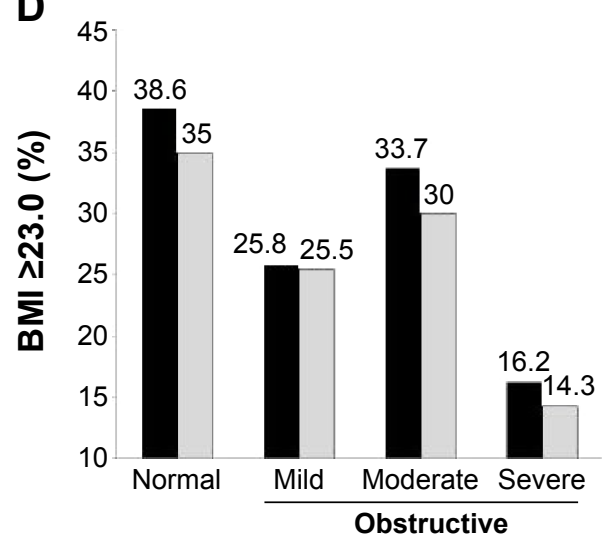

\section{E 25}

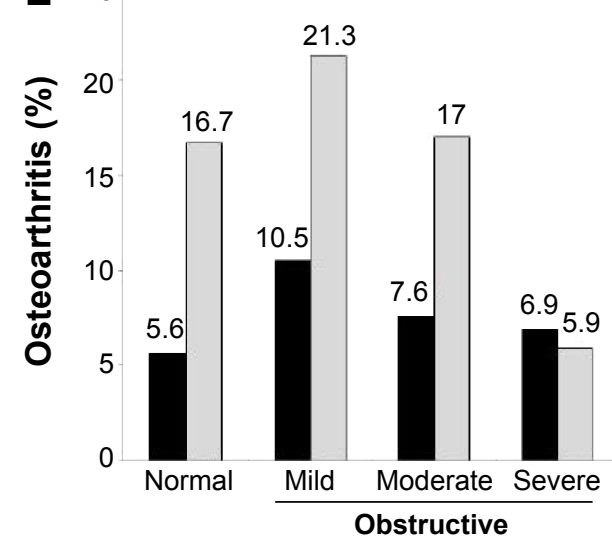

Men $\square$ Women

Figure 2 Prevalence of hypertension (A), DM (B), underweight (C) and overweight (D), and osteoarthritis (E) by sex and severity of obstructive airflow limitation. Notes: Normal $=\mathrm{FEV} / \mathrm{FVC} \geq 70 \%$ and FEV $1 \geq 80 \%$ predicted; obstructive $=\mathrm{FEV} / \mathrm{FVC}<70 \%$; mild $=\mathrm{FEV}_{1} \geq 80 \%$ predicted; moderate $=50 \% \leq \mathrm{FEV},<80 \%$ predicted; severe $\mathrm{FEV}_{1}<50 \%$ predicted.

Abbreviations: BMI, body mass index; DM, diabetes mellitus; $\mathrm{FEV}_{1}$, forced expiratory volume in I second; FVC, forced vital capacity

increasing age and smoking are the most important factors in COPD. In this study, the prevalence of hypertension was $49.6 \%$. Moreover, the findings showed that the prevalence of hypertension increases with the severity of obstruction, regardless of sex (Figure 2A).
DM occurs frequently in COPD and is being increasingly reported in many studies, and the prevalence is reported as approximately $10 \%-25 \% .^{12,23,24,29}$ The association between the two diseases is not identified precisely, although it is believed to be a consequence of systemic inflammation. ${ }^{30}$ 
A

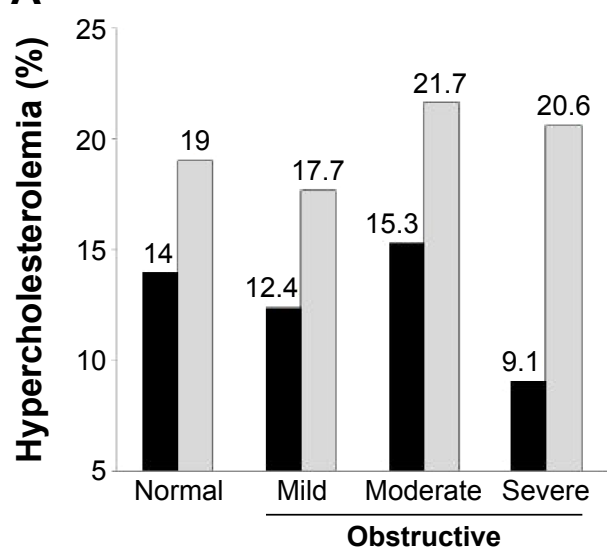

C

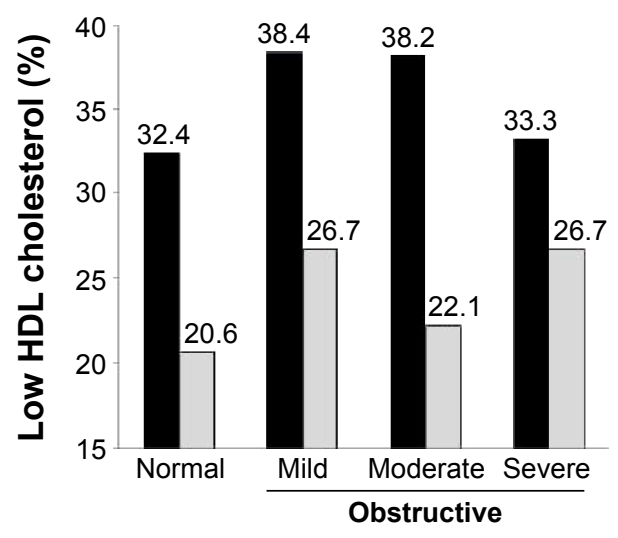

B

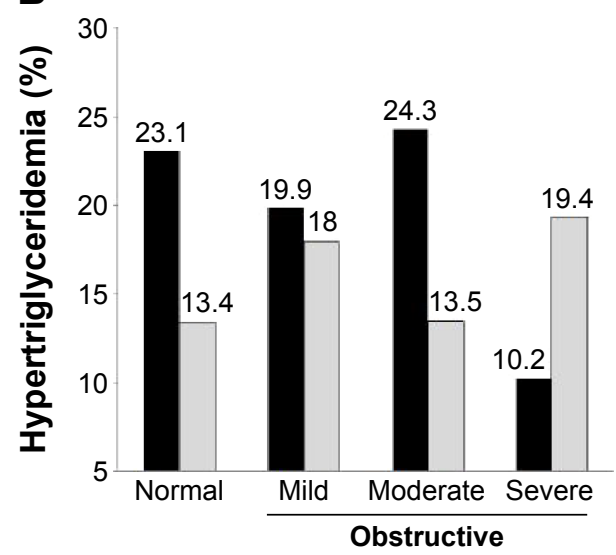

D

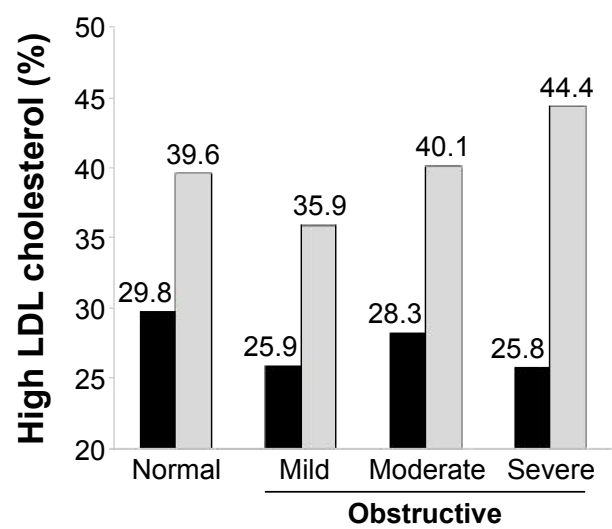

Men $\square$ Women

Figure 3 Prevalence of hypercholesterolemia (A), hypertriglyceridemia (B), low HDL cholesterol (C), and high LDL cholesterol (D), by sex and severity of obstructive airflow limitation.

Notes: Normal $=$ FEV $/$ FVC $\geq 70 \%$ and FEV $\geq 80 \%$ predicted; Obstructive $=$ FEV $/$ FVC $<70 \%$; Mild $=$ FEV,$\geq 80 \%$ predicted; moderate $=50 \% \leq \mathrm{FEV},<80 \%$ predicted; severe $\mathrm{FEV}_{1}<50 \%$ predicted.

Abbreviations: $\mathrm{FEV}_{1}$, forced expiratory volume in I second; FVC, forced vital capacity; HDL, high-density lipoprotein; LDL, low-density lipoprotein.

DM in patients with COPD is caused partly by common genetic, lifestyle, and environmental factors, as well as the use of systemic corticosteroids, which are used to control lung inflammation in COPD. ${ }^{31,32}$ In a previous study in Korea, the prevalence of DM was shown to be $16.6 \% .{ }^{15} \mathrm{DM}$ has no correlation with the severity of airflow limitation, and is more common in men. ${ }^{25}$ In this study, the prevalence of DM was $16.8 \%$, and it was more common depending on the severity (except in the severe group), while it showed less prevalence in females (Figure 2B). Low prevalence of DM in COPD can be affected by low BMI, ${ }^{33}$ which increases in patients with severe airway obstruction.

Dyslipidemia is one of several parameters employed to diagnose metabolic syndrome. A previous study reported that the prevalence of dyslipidemia in COPD was approximately $36 \%-52 \%{ }^{23,27}$ Dyslipidemia is one of the major comorbidities in COPD; however, most studies have not demonstrated differences in the prevalence of dyslipidemia between COPD and control subjects. ${ }^{34}$ Otherwise, Joo et al ${ }^{15}$ reported that the prevalence of dyslipidemia in COPD was $31.7 \%$, which was lower than that in non-COPD subjects. They defined dyslipidemia as an LDL cholesterol level $\geq 130 \mathrm{mg} / \mathrm{dL}$. In our study, the prevalence of dyslipidemia was $72.7 \%$, which was higher than that in the normal lung function group. This difference is rooted in the definition of dyslipidemia. As in the previous study, our study showed that high LDL cholesterol was less common in the obstructive lung function group than in the normal lung function group. However, the prevalence of hypertriglyceridemia and low HDL cholesterol was higher in the obstructive lung function group than in the normal lung function group. Characteristically, the prevalence of all forms of dyslipidemia decreased in the severe group (Table 2). This phenomenon appears prominently in men. Low BMI would have a profound influence on results. A general increasing 
trend marks the prevalence of dyslipidemia, with increasing BMI in both men and women with age. ${ }^{35,36}$ However, in women, it increased rather than decreased in the severe group, despite a finding that underweight was predominant in the severe obstructive lung function group (Figure 3). This might be due to the mild severity of airway obstruction and racial/ethnic differences, ${ }^{37}$ or the low percentage of smokers and old age in female COPD patients.

Anemia is usually seen in $10 \%-30 \%$ of COPD patients. ${ }^{38}$ Anemia is a cause of dyspnea and contributes to functional limitation in anemic patients. The mechanism by which patients with COPD develop anemia remains unclear. Systemic inflammation, neurohormonal activation - both of which are associated with smoking and cardio-renal syndrome, which involves activation of the renin-angiotensin-aldosterone system, were thought to be the mechanisms causing anemia in COPD patients. ${ }^{39}$ In Korea, the prevalence of anemia in the obstructive lung function group was previously found to be $7.6 \%$; our study also showed a prevalence of $7.6 \%$. John et $\mathrm{al}^{40}$ reported that, because of hypoxia, patients with advanced COPD showed significantly higher hemoglobin values and lower prevalence of anemia than did patients with COPD in stage 0 . In our study, there was no association with severity in both men and women. Mean hemoglobin level was approximately $14.9-15.0 \mathrm{~g} / \mathrm{dL}$ in men, and approximately $13.0-13.3 \mathrm{~g} / \mathrm{dL}$ in women at all stages of obstruction. Moreover, there was no difference in the prevalence of anemia relative to the severity of COPD. These prevalence findings may be contingent upon patient characteristics and the diagnostic criteria used. ${ }^{41}$ Women were significantly more likely than men to be anemic (6.2\% vs 9.5\%); when the subject population was divided into men and women, women from the obstructive lung function group did not show differences from the normal lung function group (men: $3.7 \%$ vs $6.2 \% ; P<0.001$, women: $11.8 \%$ vs $9.5 \% ; P<0.306)$. We considered that the effects of other causes (eg, menopause, other chronic diseases) are more clinically important than those of systemic inflammation of COPD in women $\geq 40$ years old. Further studies are needed on this topic. To our knowledge, this is the first study to have mentioned the relationship between anemia, severity of COPD, and sex.

Osteoporosis is a major comorbidity in COPD. ${ }^{7}$ It is also associated with poor health status and prognosis. Osteoporosis is more common in subjects with low BMI and low fat-free mass. ${ }^{42,43}$ A higher GOLD stage and a low $\mathrm{FEV}_{1}$ have been shown to be related to osteoporosis in the presence of low bone mineral density (BMD). ${ }^{44,45}$ Physical inactivity, smoking, poor diet, and systemic corticosteroids seem to have important effects on osteoporosis. Again, systemic inflammation in COPD patients can be a risk factor in osteoporosis. ${ }^{46}$ The prevalence of osteoporosis in COPD is $8.4 \%-69 \%$, and the prevalence of osteopenia is $28 \%-67 \%{ }^{47}$ In Korea, an osteoporosis prevalence of $7.9 \%$ was reported in COPD patients. ${ }^{15}$ This difference may be due to differences in patient characteristics and ethnicity. Our study also showed a high prevalence of osteoporosis among patients in the severe obstructive lung function group. However, the prevalence of osteopenia was lower than that in the normal lung function group (Table 2). Because the number of cases of osteopenia and osteoporosis in the severe obstructive lung function group was too small for accurate determination, it is necessary to perform studies with more subjects.

There are some studies that have reported the association between COPD and arthritis. The rate of osteoarthritis in patients with COPD has been shown to be $22 \%-70 \%{ }^{48,49}$ In almost all of these studies, arthritis was defined via selfreport, or the researchers studied only rheumatic arthritis. A previous study in Korea found no association between arthritis and COPD, although that study was dependent upon questionnaires. ${ }^{15}$ Our study excluded the subjective symptoms of the patient, and diagnosed arthritis by using a radiological objective image; $11.9 \%$ of COPD subjects had osteoarthritis. More than half (61.1\%) of these cases were accompanied by symptoms (data were not shown). To our knowledge, this is the first study that has mentioned the relationship between osteoarthritis, severity of COPD, and sex.

In this study, we investigated the relationship between COPD airflow limitation severity and comorbidities with objective measurements. Echave-Sustaeta et $\mathrm{al}^{50}$ mentioned that severity is not an independent predictor of comorbidity. However, we showed that many comorbidities were associated with severity. Our study had several strengths. First, we used data from a nationwide survey, with a nationally representative stratified random sample that was comprised of various objective data points. Thus, we could use a much larger sample size than other studies. We also obtained the data on comorbidities (eg, arthritis, osteroporosis) by laboratory tests and image study, not only interviews. Second, to our knowledge, this is the first study that was analyzed separately for both sex and severity. Third, we did not exclude restrictive lung disease subjects. Therefore, our study showed characteristics of the subjects with restrictive lung disease.

However, this study had some limitations. First, although this was a prevalence study of comorbidities in COPD, there was no analysis about other important comorbidities such as 
cardiovascular disease and cancer because no objective data were available regarding these diseases. While previous studies of COPD comorbidities were based on interviews, this study was carried out on the basis of laboratory tests, image studies, and physical examination. Even though questionnaires included questions on the history of cardiovascular disease, depression, lung cancer, pulmonary tuberculosis, asthma, and allergic rhinitis, they were not objective. For that reason, we did not use this information in our study. So we just described these comorbidities according to a selfreported questionnaire on Table S1. Second, we included subjects with airway obstruction caused by other diseases, such as pulmonary tuberculosis, bronchiectasis, and asthma. This could have overdetermined the number of subjects with airway obstruction. Third, our spirometry data were prebronchodilator spirometry data. Fourth, disease severity in most subjects with airway obstructive disease was classified as either mild or moderate. When divided into men and women, many parameters had fewer than five subjects in the severe airway obstructive lung disease group, a circumstance that could have affected the result.

\section{Conclusion}

In conclusion, this study showed that hypertension and underweight are common comorbid diseases in COPD patients, and are more increased as the severity of airflow obstruction increased in both men and women. DM, hypertriglyceridemia, and low HDL cholesterol are also more common in subjects with airway obstruction, although their prevalence is lower in subjects with severe airway obstruction.

\section{Author contributions}

Hee Jin Park, contributed to the study design, data analysis and interpretation, and writing of this manuscript.

Ah Young Leem, contributed to the study design, data analysis and interpretation, and review of this manuscript.

Sang Hoon Lee, contributed to the study design, data analysis and interpretation, and review of this manuscript.

Ju Han Song, contributed to the study design, data analysis and interpretation, and review of this manuscript.

Moo Suk Park, contributed to the study design, data analysis and interpretation, and review of this manuscript.

Young Sam Kim, contributed to the study design, data analysis and interpretation, and review of this manuscript.

Se Kyu Kim, contributed to the study design, data analysis and interpretation, and writing of this manuscript.

Joon Chang, contributed to the study design, data analysis and interpretation, and writing of this manuscript.
Kyung Soo Chung, contributed to the study design, data analysis and interpretation, and writing of this manuscript.

\section{Disclosure}

The authors report no conflicts of interest in this work.

\section{References}

1. Global Initiative for Chronic Obstructive Lung Disease. Global Strategy for the Diagnosis, Management, and Prevention of Chronic Obstructive Pulmonary Disease. Global Initiative for Chronic Obstructive Lung Disease; 2014.

2. Mannino DM, Buist AS. Global burden of COPD: risk factors, prevalence, and future trends. Lancet. 2007;370:765-773.

3. Mathers CD, Loncar D. Projections of global mortality and burden of disease from 2002 to 2030. PLoS Med. 2006;3:e442.

4. Vestbo J, Hurd SS, Rodriguez-Roisin R. The 2011 revision of the global strategy for the diagnosis, management and prevention of COPD (gold) - why and what? Clin Respir J. 2012;6:208-214.

5. Miller MR, Hankinson J, Brusasco V, et al. Standardisation of spirometry. Eur Respir J. 2005;26:319-338.

6. Consultation WHOE. Appropriate body-mass index for asian populations and its implications for policy and intervention strategies. Lancet. 2004;363:157-163.

7. Fabbri LM, Luppi F, Beghe B, Rabe KF. Complex chronic comorbidities of COPD. Eur Respir J. 2008;31:204-212.

8. Soriano JB, Visick GT, Muellerova H, Payvandi N, Hansell AL. Patterns of comorbidities in newly diagnosed COPD and asthma in primary care. Chest. 2005;128:2099-2107.

9. Wagner PD. Possible mechanisms underlying the development of cachexia in COPD. Eur Respir J. 2008;31:492-501.

10. Vanfleteren LE, Spruit MA, Groenen M, et al. Clusters of comorbidities based on validated objective measurements and systemic inflammation in patients with chronic obstructive pulmonary disease. Am J Respir Crit Care Med. 2013;187:728-735.

11. Mannino DM, Thorn D, Swensen A, Holguin F. Prevalence and outcomes of diabetes, hypertension and cardiovascular disease in COPD. Eur Respir J. 2008;32:962-969.

12. Curkendall SM, DeLuise C, Jones JK, et al. Cardiovascular disease in patients with chronic obstructive pulmonary disease, Saskatchewan Canada cardiovascular disease in COPD patients. Ann Epidemiol. 2006; 16:63-70.

13. Miller J, Edwards LD, Agusti A, et al; Evaluation of CLtIPSEI. Comorbidity, systemic inflammation and outcomes in the eclipse cohort. Respir Med. 2013;107:1376-1384.

14. Tan WC, Ng TP. COPD in Asia: where east meets west. Chest. 2008; 133:517-527.

15. Joo H, Park J, Lee SD, Oh YM. Comorbidities of chronic obstructive pulmonary disease in koreans: a population-based study. J Korean Med Sci. 2012;27:901-906.

16. Steuten LM, Creutzberg EC, Vrijhoef HJ, Wouters EF. COPD as a multicomponent disease: inventory of dyspnoea, underweight, obesity and fat free mass depletion in primary care. Prim Care Respir J. 2006;15:84-91.

17. Kim SB, Kang YA, Jung JY, et al. Body mass index and fat free mass index in obstructive lung disease in Korea. Int J Tuberc Lung Dis. 2014;18: 102-108.

18. Baarends EM, Schols AM, Pannemans DL, Westerterp KR, Wouters EF. Total free living energy expenditure in patients with severe chronic obstructive pulmonary disease. Am J Respir Crit Care Med. 1997;155: 549-554.

19. Debigare R, Marquis K, Cote $\mathrm{CH}$, et al. Catabolic/anabolic balance and muscle wasting in patients with COPD. Chest. 2003;124:83-89.

20. Eid AA, Ionescu AA, Nixon LS, et al. Inflammatory response and body composition in chronic obstructive pulmonary disease. Am J Respir Crit Care Med. 2001;164:1414-1418. 
21. Celli BR, Cote CG, Marin JM, et al. The body-mass index, airflow obstruction, dyspnea, and exercise capacity index in chronic obstructive pulmonary disease. $N$ Engl J Med. 2004;350:1005-1012.

22. Landbo C, Prescott E, Lange P, Vestbo J, Almdal TP. Prognostic value of nutritional status in chronic obstructive pulmonary disease. Am J Respir Crit Care Med. 1999;160:1856-1861.

23. Divo M, Cote C, de Torres JP, et al. Comorbidities and risk of mortality in patients with chronic obstructive pulmonary disease. Am J Respir Crit Care Med. 2012;186:155-161.

24. Mapel DW, Dedrick D, Davis K. Trends and cardiovascular comorbidities of COPD patients in the veterans administration medical system, 1991-1999. COPD. 2005;2:35-41.

25. Agusti A, Calverley PM, Celli B, et al; Evaluation of CLtIPSEi. Characterisation of COPD heterogeneity in the eclipse cohort. Respir Res. 2010; $11: 122$.

26. Baty F, Putora PM, Isenring B, Blum T, Brutsche M. Comorbidities and burden of COPD: A population based case-control study. PLoS One. 2013;8:e63285.

27. Smith MC, Wrobel JP. Epidemiology and clinical impact of major comorbidities in patients with COPD. Int J Chron Obstruct Pulmon Dis. 2014;9:871-888.

28. Holguin F, Folch E, Redd SC, Mannino DM. Comorbidity and mortality in COPD-related hospitalizations in the United States, 1979 to 2001 Chest. 2005;128:2005-2011.

29. Barr RG, Celli BR, Mannino DM, et al. Comorbidities, patient knowledge, and disease management in a national sample of patients with COPD. Am J Med. 2009;122:348-355.

30. Fabbri LM, Rabe KF. From COPD to chronic systemic inflammatory syndrome? Lancet. 2007;370:797-799.

31. Chatila WM, Thomashow BM, Minai OA, Criner GJ, Make BJ. Comorbidities in chronic obstructive pulmonary disease. Proc Am Thorac Soc. 2008;5:549-555.

32. Spies CM, Strehl C, van der Goes MC, Bijlsma JW, Buttgereit F. Glucocorticoids. Best Pract Res Clin Rheumatol. 2011;25:891-900.

33. Lavi S, Prasad A, Yang EH, et al. Smoking is associated with epicardial coronary endothelial dysfunction and elevated white blood cell count in patients with chest pain and early coronary artery disease. Circulation. 2007;115:2621-2627.

34. Basili S, Ferroni P, Vieri M, et al. Lipoprotein(a) serum levels in patients affected by chronic obstructive pulmonary disease. Atherosclerosis. 1999; 147:249-252.

35. Humayun A, Shah AS, Alam S, Hussein H. Relationship of body mass index and dyslipidemia in different age groups of male and female population of Peshawar. J Ayub Med Coll Abbottabad. 2009;21:141-144.

36. Malnick SD, Knobler H. The medical complications of obesity. QJM. 2006;99:565-579.

37. Izquierdo JL, Martinez A, Guzman E, de Lucas P, Rodriguez JM. Lack of association of ischemic heart disease with COPD when taking into account classical cardiovascular risk factors. Int J Chron Obstruct Pulmon Dis. 2010;5:387-394.
38. Silverberg DS, Mor R, Weu MT, Schwartz D, Schwartz IF, Chernin G Anemia and iron deficiency in COPD patients: prevalence and the effects of correction of the anemia with erythropoiesis stimulating agents and intravenous iron. BMC Pulm Med. 2014;14:24.

39. Similowski T, Agusti A, MacNee W, Schonhofer B. The potential impact of anaemia of chronic disease in COPD. Eur Respir J. 2006;27: 390-396.

40. John M, Lange A, Hoernig S, Witt C, Anker SD. Prevalence of anemia in chronic obstructive pulmonary disease: comparison to other chronic diseases. Int J Cardiol. 2006;111:365-370.

41. Boutou AK, Hopkinson NS, Polkey MI. Anaemia in chronic obstructive pulmonary disease: an insight into its prevalence and pathophysiology. Clin Sci. 2015;128:283-295.

42. Bolton CE, Cannings-John R, Edwards PH, et al. What community measurements can be used to predict bone disease in patients with COPD? Respir Med. 2008;102:651-657.

43. Bolton CE, Ionescu AA, Shiels KM, et al. Associated loss of fat-free mass and bone mineral density in chronic obstructive pulmonary disease. Am J Respir Crit Care Med. 2004;170:1286-1293.

44. Kjensli A, Mowinckel P, Ryg MS, Falch JA. Low bone mineral density is related to severity of chronic obstructive pulmonary disease. Bone. 2007;40:493-497.

45. Vrieze A, de Greef MH, Wijkstra PJ, Wempe JB. Low bone mineral density in COPD patients related to worse lung function, low weight and decreased fat-free mass. Osteoporos Int. 2007;18:1197-1202.

46. Gan WQ, Man SF, Senthilselvan A, Sin DD. Association between chronic obstructive pulmonary disease and systemic inflammation a systematic review and a meta-analysis. Thorax. 2004;59:574-580.

47. Graat-Verboom L, Wouters EF, Smeenk FW, van den Borne BE, Lunde R, Spruit MA. Current status of research on osteoporosis in COPD: a systematic review. Eur Respir J. 2009;34:209-218.

48. Mapel DW, Hurley JS, Frost FJ, Petersen HV, Picchi MA, Coultas DB. Health care utilization in chronic obstructive pulmonary disease. A casecontrol study in a health maintenance organization. Arch Intern Med. 2000;160:2653-2658.

49. Schnell K, Weiss CO, Lee T, et al. The prevalence of clinically-relevant comorbid conditions in patients with physician-diagnosed COPD: a cross-sectional study using data from NHANES 1999-2008. BMC Pulm Med. 2012;12:26.

50. Echave-Sustaeta JM, Casanova LC, Cosio BG, Soler-Cataluña JJ, Garcia-Lujan R. Comorbidity in chronic obstructive pulmonary disease. Related to disease severity? Int J Chron Obstruct Pulmon Dis. 2014;9: 1307-1314. 


\section{Supplementary material}

Table SI Comorbidities according to self-reported questionnaire

\begin{tabular}{|c|c|c|c|c|c|c|c|}
\hline \multirow[t]{3}{*}{ Comorbidity } & \multirow[t]{2}{*}{ Normal } & \multirow[t]{2}{*}{ Restrictive } & \multirow[t]{2}{*}{ Obstructive } & \multicolumn{3}{|c|}{ Obstructive severity } & \multirow[t]{3}{*}{$P$-value } \\
\hline & & & & Mild & Moderate & Severe & \\
\hline & 1 2,224 (75.6\%) & $1,819$ ( $11.3 \%)$ & $2,108(13.1 \%)$ & $954(45.3 \%)$ & I,042 (49.4\%) & I I 2 (5.3\%) & \\
\hline \multicolumn{8}{|l|}{ Cardiovascular disease } \\
\hline Ischemic heart disease & $321(2.6)$ & $82(4.5)$ & $80(3.8)$ & $33(3.5)$ & $43(4.1)$ & $4(3.6)$ & $<0.001$ \\
\hline Angina pectoris & $238(1.9)$ & $53(2.9)$ & $44(2.1)$ & $20(2.1)$ & $22(2.1)$ & $2(1.8)$ & 0.037 \\
\hline Myocardial infarction & $10 \mid(0.8)$ & $33(1.8)$ & $38(1.8)$ & $14(1.5)$ & $22(2.1)$ & $2(1.8)$ & $<0.001$ \\
\hline Stroke & $118(1.0)$ & $64(3.5)$ & $63(3.0)$ & $28(2.9)$ & $30(2.9)$ & $10(8.9)$ & $<0.001$ \\
\hline Depression & I,922 (I5.7) & $289(15.9)$ & $265(12.6)$ & $115(12.1)$ & $130(12.5)$ & $20(17.9)$ & $<0.001$ \\
\hline Lung cancer & $3(0.0)$ & $7(0.4)$ & $9(0.4)$ & $\mathrm{I}(0 . \mathrm{I})$ & $7(0.7)$ & I (0.9) & $<0.001$ \\
\hline Pulmonary tuberculosis & $604(4.9)$ & $163(9.0)$ & $229(10.9)$ & $92(9.6)$ & $168(16.1)$ & $39(34.8)$ & $<0.001$ \\
\hline Asthma & $366(3.0)$ & $108(5.9)$ & $273(13.0)$ & $67(7.0)$ & $153(14.7)$ & $53(47.3)$ & $<0.001$ \\
\hline Allergic rhinitis & $415(3.4)$ & $74(4.1)$ & $67(3.2)$ & $24(2.5)$ & $4 \mid(3.9)$ & $2(1.8)$ & 0.734 \\
\hline
\end{tabular}

Notes: Data are presented as numbers (percentages) for categorical variables. Normal $=\mathrm{FEV}_{1} / \mathrm{FVC} \geq 70 \%$ and $\mathrm{FEV}, \geq 80 \%$ predicted; restrictive $=\mathrm{FEV} / \mathrm{FVC} \geq 70 \%$ and $\mathrm{FEV}_{1}<80 \%$ predicted; obstructive $=\mathrm{FEV} / \mathrm{FVC}<70 \%$ predicted; mild $=\mathrm{FEV}, \geq 80 \%$ predicted; moderate $=50 \% \leq \mathrm{FEV},<80 \%$ predicted; severe $=\mathrm{FEV},<50 \%$ predicted Abbreviations: $\mathrm{FEV}_{1}$, forced expiratory volume in I second; FVC, forced vital capacity.

\section{Publish your work in this journal}

The International Journal of COPD is an international, peer-reviewed journal of therapeutics and pharmacology focusing on concise rapid reporting of clinical studies and reviews in COPD. Special focus is given to the pathophysiological processes underlying the disease, intervention programs, patient focused education, and self management protocols.
This journal is indexed on PubMed Central, MedLine and CAS. The manuscript management system is completely online and includes a very quick and fair peer-review system, which is all easy to use. Visit http://www.dovepress.com/testimonials.php to read real quotes from published authors. 